\title{
Interactive Ink-and-Wash Drawing
}

\author{
Young-Mi Kim \\ Graduate School of Advanced Imaging Science, Multimedia, and Film, \\ Chung-Ang University, 221 Huksuk-Dong, Dongjak-Ku, \\ 156-756, Seoul, Korea \\ iou50@naver.com
}

\begin{abstract}
This paper is about the study on an artwork, a Ink-and-Wash Painting that has been expressed through a digital algorithm. Ink-and-Wash Painting were popular during the Chosun era [1] reigned by kings and officials [2]. It is the intention of this paper to study the potential of expressing Ink-and-Wash Painting through interaction, and present a direction that can coincide with modern paintings by developing Ink-and-Wash Painting from a traditional aspect through analyzing the theories and techniques instilled in my work.
\end{abstract}

Keywords: Interactive drawing, Interactive Ink-and-Wash drawing, Digital Ink-and-Wash Painting, Interactive Four Gracious Plants.

\section{Introduction}

Oriental painting has pursued its aesthetic value in plant. It has symbolized the beauty and of plant leaves, branches and flowers and their implicit values. As the representative example, the Four Gracious Plants refers to plum, orchid, chrysanthemum and bamboo in oriental painting, The Four Gracious Plants [3] originally referred to the persons who has virtue, nobility and knowledge, used to pay a tribute to four generals with high dignity in the Warring States Period [4]. This word in painting was originated from applying plum, orchid, chrysanthemum and bamboo to the great persons since the Four Gracious plants were regarded as pure, noble and honorable. This implies that the model for human internal ideology is sought from the plants [5]. For this reason, the brushing of the Four Gracious Plants, as attractive materials for the noblemen, has been regarded to reflect the character of a classical scholar and as a means to develop ones personality [3]. When taking a look at Korean history, ancestors have firmly protected our tradition and culture from numerous foreign invasions and handed them down to the present generation. However, entering the brilliant digital era, it is a fact that traditional values and culture are treated as invaluable and thus neglected. Therefore, there is a need to actively utilize and fuse modern media as a means of inheriting and fostering our tradition. The purpose of this dissertation is to make the original meaning of the Ink-and-Wash Painting, the most aesthetic oriental painting, stand out as well as naturally blending it into the lives of modern people by having a different form of expression. 


\section{The Four Gracious Plants}

One of the most important characteristics of Ink-and-Wash Painting is to draw not a figure but the mind. This idea means that painting expresses the form, but its ultimate goal is to search for the mind through the forms including brushing line and trace of ink. This idea also pictorially represents the attitude to place importance on mind and disregard form. This implies that the Ink-and-Wash Painting is regarded as an art which requires high level of metaphysical philosophy or personality. In order to reinterpret the Ink-and-Wash Painting representing the idea of mental training into digital, the role of digital interface is more important than anything else. The interface that can express the mind, in other words the digital interface to replace the brush, informatizes the expressive behaviors of audience and visualizes its outcome onto the screen for the interactions with them. This paper describes the interactive artwork for two plants among the Four Gracious Plants; bamboo and orchid.

\subsection{Bamboo Concept}

Based on the concept of this work, the bamboo was painted according to the strength and the length of the breath of a daegum player. Daegum is one of the representative musical instruments that were played in palaces during Chosun Dynasty. Literary men learned how to write or paint, and also, how to play daegum. It was taken as it was believed to cultivate good minds, just like the four gracious plants. In other words, the painting is not drawn on a paper using a brush but drawn by daegum play, that is, according to the strength and the length of the breath of a daegum player. A daegum is hollow inside and therefore the sound resonates from within and comes out of chwigoo. So, the ultra tiny microphone is installed inside chwigoo, so that the computer receives and recognizes the strength and length of the breath of a player, and then classifies them into 5 different sounds. The strength of the breath determines the shading of the ink and the length of the breath determines the length of the bamboos knot [2].

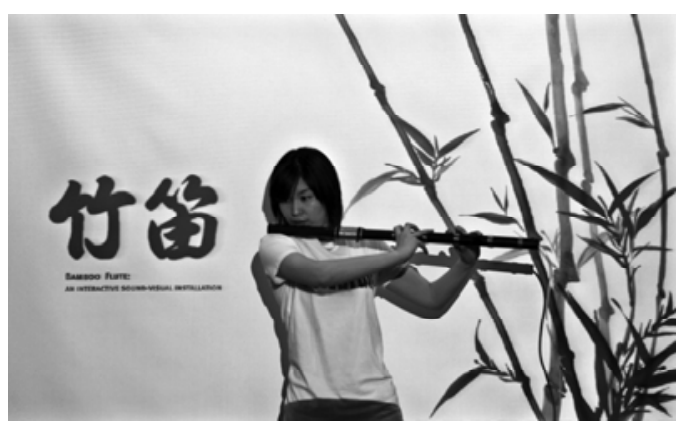

Fig. 1. The artwork as it is drawn according to a performer's play

SuDongpo (1036-1101), the famous Chinese artist, stressed that to paint a bamboo, one has to first grow a bamboo in his mind and paint it only when his mind is aligned with it [6]. The same bamboo can have a different look and feel depending on who 
has drawn it. Likewise, depending on the painters intention and emotional state, a painting could look or feel different. Just like a hand-drawn picture cannot be repeated or duplicated, any participant can draw a different picture and express his intention as he listens to different performers play.

\subsection{Orchid Concept}

During the old days in the orient, people used to wipe oriental orchid leaves or painted oriental orchid for mental training by having an oriental orchid always by their side. Once each orchid is wiped off, the things troubling ones mind is forgotten and ones heart is emptied. Through the act of wiping orchid leaves with utmost care, an orchid instilled with ancient philosophical ideas is visualized. Just as God breathed life into human nostrils and created a living life form, an orchid flower with an excellent fragrance is visualized when a breath is breathed into an orchid flower [7].
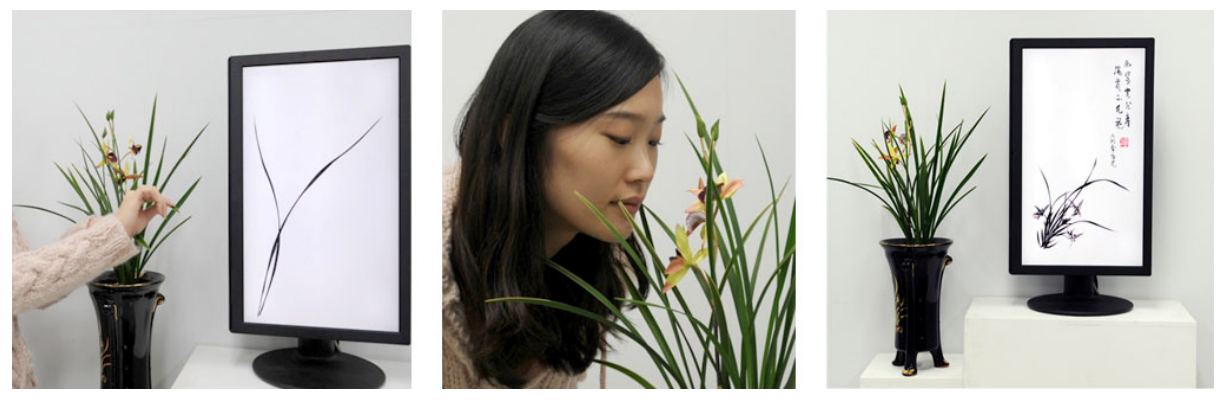

Fig. 2. (a)The orchid leaf is drawn at the same angle as the bending angle used when the participant rubs the orchid leaf (b)The flower is drawn when the participant smells the flower (c)Complete of drawing

When an orchid leaf is selected and wiped using the thumb and index finger as if sweeping it down, an orchid leaf is drawn one after another inside the digital frame. A bend sensor is attached behind orchid leaves, and the size of an angle made while an orchid leaf is curved appears due to the difference in electrical current through bend sensors. When the angle of the curve communicated through the orchid leaf is big, the orchid leaf in the painting is drawn as curved leaves or leaves blowing in the wind. The user employs rubbing motions to make various designs, through which the user may create a balance between the orchid and the blank space. After drawing the orchid leaf, the flower is drawn. The flower of the orchid is simple, with only one or two bunches. The fragrance is elegant and delicate, and these graceful qualities attract the attention of the viewer. For this reason, the primary interface with the flower is olfactory rather than tactile. When digilog orchid users smell the flower, the flower generates various images according to its strength When the interactive work is finished, a caption or a poem that goes well with the style of the painting is written in the remaining blank space with a stamped red seal. All of these methods communicate that the painting was produced in the same way orchid paintings were painted in the old days. The regularity and creativity of the orchid painting striking a balance, 
writing a poem and writing which goes well with the blank space, the seal of the artist, and above all, the greatest significance is that interaction was achieved through the act of wiping the orchid leaves with the attitude and spirituality of the person drawing the painting [7][8].

\section{Conclusions}

Ink-and-Wash Painting representing oriental art is a collection of a diverse range of art that can be enjoyed along with the beauty of poems, calligraphies, and seals within the painting. This is an artwork for examining the spirituality and figurative perception of oriental art, finding and succeeding a modern way of expression which was completed by achieving mutual harmony between analog contents and digital technology. The painting in this artwork should be painted in a leisurely way just like when one drinks tea after tea leaves have been sufficiently soaked. Only then one can feel the deep taste and aroma and experience the slow art. If we appreciate this work in the similar way, we get close to the thoughts and lives of the painters of those times who used to draw the four gracious plants.

\section{References}

1. The Joseon Dynasty of Korea lasted more than 519 years (1392 1910) and encompassed the reigns of 27 kings. During this time, which ink-and-wash painting flourished and became highly developed

2. Kim, Y.M., Choi, J.S.: Breathe Brush. In: 37th ACMSIGGRAPH 2010, Los Angeles, July 25-29 (2010)

3. Article on Chinese painting with the 4 flowers and their symbolism,

http: / /www. chinatownconnection.com/

chinese-traditional-paintings.htm

4. The ancient Chinese reformation period from B.C. 8 century to B.C. 3 century

5. Tominibu, I., Cho, S.m.: Oriental painting. Dahal Media, Korea, Repubilc of (2005)

6. Kim, Y.-M., Choi, J.-S.: The Sound Brush Made of Bamboo. In: Butz, A., Fisher, B., Christie, M., Krüger, A., Olivier, P., Therón, R. (eds.) SG 2009. LNCS, vol. 5531, pp. 279 282. Springer, Heidelberg (2009)

7. Kim, Y., Choi, J.: Affective Interacting Art. In: Yang, H.S., Malaka, R., Hoshino, J., Han, J.H. (eds.) ICEC 2010. LNCS, vol. 6243, pp. 413-415. Springer, Heidelberg (2010)

8. Kim, Y.M., Choi, J.S.: Ink-and-Wash Painting Oriental Cymbidium Drawn with the Tip of the Fingers. In: 37th ACMSIGGRAPH 2010, Los Angeles, July 25-29 (2010) 